$\mathrm{P} \& \mathrm{~A}$ Año $2, \mathrm{~N}^{\circ} 2$

enero-junio de 2017

pp. 5-15

\title{
Resumen
}

En este ensayo se sostiene la posibilidad y pertinencia de realizar investigación académica en el campo de la actividad proyectual en Arquitectura. Dicha investigación, de hecho, se realiza; no obstante, goza de escaso reconocimiento en el ámbito académico, en el cual suele considerarse que el conocimiento auténtico solo se adquiere por medio de la investigación científica. Asimismo, se destaca la naturaleza de los tipos de investigación aplicables y se reflexiona sobre el conocimiento producido a través del proyectar arquitectura. Se discuten sus argumentos epistemológicos y metodológicos, en el afán de evidenciar cómo satisface los requerimientos de cualquier investigación académica; en especial, se discurre sobre el lenguaje de las imágenes, sustancial en este tipo de investigación. Finalmente, se confirma su capacidad de plantear interrogantes articuladas, resolver problemas, establecer el estado del arte específico y, contribuir al crecimiento del área de conocimiento aplicando métodos validados, en su lenguaje natural de comunicación.

Palabras clave: Investigación académica, arquitectura, proyecto, diseño arquitectónico

\section{La investigación en la actividad proyectual de la arquitectura. Objeto y método*}

\author{
Research within architectural design activities. Purpose and method \\ Msc. Arq. Juan de Dios Salas Canevaro**
}

Recibido: 10 de abril de 2017

Aceptado: 5 de junio de 2017

\begin{abstract}
This essay holds the posibility and pertinence of carrying out academic research in the field of architectural design activity. Although such research does occur, it enjoys limited recognition in the academy, for which authentic knowledge can only be acquired through scientific research. As well, the essay highlights the nature of the types of research applicable within architecture and reflects on the knowledge created through design in architecture. It discusses their epistemological and methodological arguments, with the desire to demonstrate how it satisfies the requirements of any academic investigation. In particular, it considers the language of images, which is substantial in this type of research. Finally, it confirms the ability of the abovementioned research to raise articulated questions, solve problems, establish its specific state of the art and, consequently, contribute to the growth of this field of knowledge, applying methods validated in its natural language of communication.
\end{abstract}

Keywords: Academic research, architecture, project, architectural design

\footnotetext{
* El articulo recoge la experiencia docente y de investigación del autor desarrollada en las universidades de Venezuela y el Perú entre el 2009 y 2016. Es una investigación autofinanciada. Se declara no tener conflicto de intereses en la publicación de este artículo.

** Arquitecto por la Universidad Ricardo Palma, máster en Regional Planning, Universidad de Syracuse, Nueva York, con estudios de posgrado en Arquitectura Universidad Ricardo Palma. Profesor titular de la Facultad de Arquitectura y Diseño de la Universidad de Los Andes, Mérida, Venezuela, y profesor de la Facultad de Arquitectura y Urbanismo de la URP. Investigador en las áreas de Arquitectura, Diseño Urbano y Planificación Urbana.
} 


\section{Usus magister est optimus.}

La pretensión de este ensayo es tratar un tema que desde hace algunos años está rodeado de una creciente inquietud en el ámbito académico de la Arquitectura: la identidad de la investigación en la disciplina. Esta ha estado sujeta a variadas interpretaciones que la impregnan de un alto nivel de incertidumbre. Trabajos de investigación, tesis, artículos científicos y publicaciones especializadas son algunos de los productos que recogen de tal incertidumbre. Esta invita a presentar y discutir el tema, con el objetivo de propiciar el desarrollo, difusión y validación de teorías, enfoques, metodologías y resultados de la disciplina de la Arquitectura desde una perspectiva académica.

Las recientes políticas públicas de educación superior otorgan a la investigación una función primordial en las universidades, para la formación profesional, lo cual, sin duda, reaviva el debate sobre sus thelos y alcances en los diferentes campos del saber. La disciplina de la Arquitectura no es ajena a este debate: quienes se dedican al desarrollo del saber en dicha área perciben la necesidad de aclarar los aspectos ontológicos, epistemológicos y metodológicos de la investigación en este campo, pues se enfrentan a dificultades para insertar su trabajo de investigación en el ámbito académico en general.

Siendo la actividad proyectual del arquitecto por antonomasia la sustancia primigenia de su identidad en el interior de los ámbitos profesional y académico, es relevante discutir la naturaleza de la investigación que en ella se produce para poder responder a la interrogante de si es posible y pertinente realizar investigación en tal actividad.

\section{¿Es posible hacer investigación académica en la actividad proyectual del arquitecto?}

Existen quienes sostienen que la definición etimológica del vocablo investigar está referido al término latín vestigium, que significa "vestigio" (huella o rastro), el cual integrado al prefijo in da origen al vocablo investigar, que implica descubrir, adentrarse en las hue- llas y, por extensión, seguirlas. Otros encuentran sus raíces en el vocablo latín investigatio, que significa búsqueda, descubrimiento, exploración o examen. En ambos casos, existe consenso en que la cualidad del vocablo en cuestión está referida a hechos sujetos a observación previa y experimentación sobre los que se reúne evidencias en el camino de la indagación.

En el ámbito académico el concepto investigar ha tomado un sendero dirigido a la búsqueda del saber; no obstante, existe una suerte de predominio del concepto en relación con la ciencia. La llamada investigación científica es, para algunos universitarios, el único tipo de investigación académicamente válido. Este enfoque ha dejado en una condición de minusvalía un conjunto de campos del saber que no tratan primariamente con situaciones que hayan dejado huellas, sino con otras que aún estarían por dejarlas. Algunos de estos se debaten en una estéril lucha por el reconocimiento de sus investigaciones como dotadas de valor científico.

Se examinará ahora cómo desde la corriente filosófica del positivismo se entroniza en el medio académico la concepción de que el conocimiento auténtico solo se puede validar por medio de la comprobación de hipótesis vía aplicación del método científico, es decir, bajo la observación y la experimentación sustentadas en la modelación matemática y la estadística:

Desde que el empirismo primero y el positivismo más tarde establecieron las bases del denominado método científico, se ha naturalizado una relación de carácter unívoca entre investigación científica e investigación. En este vínculo la investigación científica sería aquella que de una manera $u$ otra se basa en la observación -se supone que objetiva- de un fenómeno y, sobre la que, mediante la aplicación de una serie de mecanismos de control y fiabilidad, se trata de que las condiciones de la investigación y sus resultados puedan ser reproducibles, verificables, extrapolables, generalizables y aplicables.

El arraigo de esta tradición como forma legítima de considerar lo que es (y no es) investigación ha llevado por ejemplo a considerar 
que son sólo los científicos vinculados a las Ciencias Experimentales quienes realizan investigación (de verdad), y a establecer una visión/posición jerárquica de éstos respecto, por ejemplo, a los científicos sociales o a quienes realizan su tarea en el campo de las Humanidades. (Hernández, 2008, pp. 87-88)

En la actividad proyectual de la arquitectura -como en la de las ingenierías y las artes-, en cambio, la esencia de su producción se sitúa en una realidad por crear. Su argumento ontológico está referido al desarrollo del conocimiento desde prefiguraciones de una realidad por existir. Es precisamente desde tal argumento que se deriva el concepto de proyecto como su producto primario. Esto es lo que en palabras de Chacón (2013) se definiría como proyecto:

Proyectar, de hecho, significa lanzar, dirigir hacia adelante, del latín proiectare, 'lanzar adelante'. El proyecto lanza una idea presente al futuro para su concreción. Aun cuando el proyecto puede ser un producto material de gran elaboración, es algo incompleto y logra su realización en el momento en que se convierte en hecho. Es por eso que el thelos de todo proyecto arquitectónico, por ejemplo, es la edificación (p. 42).

En efecto, el concepto de proyecto linda más con el de la realidad como aggiornamento de las posibilidades de lo real que con la verdad como alcance de conocimiento de esta. El proyecto es en esencia una realidad en gestación (tal como lo sería un feto en el vientre materno) que se materializará más adelante, cuando se lleve a cabo la edificación prefigurada. Allí radica la estructura existencial ontológica del ente-proyecto, el cual, por lo tanto, es también un objeto preñado de realidad observable y experimentable.

Proyectar arquitectura comporta, asimismo, un encuentro con una realidad potencial creada por el arquitecto: proyecto y proyectista forman entonces una unidad indivisible en cuanto a su esencia. Es imposible separar al proyectista de lo proyectado y viceversa. Esta situación está evidentemente contrapuesta a lo que el conocimiento científico considera uno de sus postulados esenciales: la clara diferenciación entre el sujeto que inves- tiga y el objeto investigado. Por el contrario, proyectar arquitectura puede ser entendido como el acercamiento al conocimiento desde una perspectiva fenomenológica. Esta visión replantea los principios del conocimiento empírico en la vivencia particular del observador -en relación con lo observado-, ya que este deja de ser un ente pasivo, dedicado a la simple medición y recolección de datos, para convertirse en un actor participativo en el proceso de observación y comprensión del fenómeno en cuestión (Martínez \& Ríos, 2005).

La hermenéutica fenomenológica explicaría apropiadamente la naturaleza de la investigación en la actividad proyectual:

Si bien en algunas fuentes es concebida como una técnica o método de análisis de textos, aquí es descrita desde la óptica del acceso al conocimiento a través del "estudio" de las construcciones discursivas de un autor, una ciencia, una cultura, etc., con el propósito de comprender su significado (sentido), en tal sentido, la hermenéutica sostiene la no existencia de un saber objetivo, transparente ni desinteresado sobre el mundo. Tampoco el ser humano es un espectador imparcial de los fenómenos. Antes bien, cualquier conocimiento de las cosas viene mediado por una serie de prejuicios, expectativas y presupuestos recibidos de la tradición que determinan, orientan y limitan nuestra comprensión (Martínez \& Ríos, 2005, p. 12).

\section{¿Cómo se concreta la actividad proyectual del arquitecto?}

La producción arquitectónica se origina siempre en un primer nivel de creación personal, donde la imaginación del arquitecto ejerce un dominio sobre la razón:

En esencia es intuitivo, en la medida en que responde a la personal concepción del mundo subjetivo del diseñador y a su codificación genética[...]Es decir, el tema del talento innato de generación de los mecanismos mentales para ensamblar combinaciones en la producción de imágenes, prefigurar escenarios y generar las formas y escalas de los objetos en el espacio sigue vigente (Salas, 2016, p. 32).

Por tanto, el proyecto de arquitectura se engendra desde un nivel de inicio creativo que 
se plasma en las primeras imágenes del partido de diseño y, a través del proceso de fragmentaciones y recomposiciones del mismo, se concreta en su versión final para ser materializado en obra. De este modo, se traduce lo abstracto en lo concreto, y lo universal en lo particular del proyectar, una actividad típica y frecuente en el ejercicio profesional del arquitecto. Sin embargo, no toda la actividad de proyectar arquitectura requiere de una condición analítica y teórica para su existencia. Por esta razón, la condición académica no es una condición sine qua non para proyectar arquitectura (grandes obras han sido producidas por arquitectos que no tuvieron una formación académica previa en la profesión). Pero, desde luego, la histórica creación de un lenguaje propio, indispensable para la materialización de la obra, ha dado origen a la necesidad de generar un discurso sobre él.

Así como se debe reconocer que toda actividad proyectual no necesariamente es precedida por un discurso teórico -estructurador del saber en el área de la Arquitectura-, igualmente debe admitirse que el poseer un lenguaje propio, un producto verificable y códigos profesionales validados hace posible aproximarse a conocer la realidad de sus procesos y productos.

Con miras a iniciar la discusión sobre este tema, se deberá asumir que el corpus del proceso de la actividad proyectual de la arquitectura recorre tres diferentes momentos durante su transcurrir. No obstante, este proceso de creación arquitectónica no es lineal, debido a que tales momentos no necesariamente son secuenciales ni están vinculados por relaciones causa-efecto, por lo que podrían presentarse en distinto orden, de acuerdo a "el estar ahí" (Dasein) del proyectista, y a la naturaleza de lo proyectado y sus circunstancias.

El primer momento del proceso es el de la iluminación, cuando la intuición (tanto sensorial como intelectual) predomina como mecanismo de conocimiento holístico. Por esta razón, la fase de exploración entre lo realizable y lo imaginable puede resultar estresante, $y$ en ocasiones angustiante para el proyectista, de manera análoga a la creación en el ámbito de las artes visuales:
Por lo tanto, el insight o iluminación, requiere un estado de espíritu propio, conocido como mente creadora, donde el conocimiento intuitivo pueda estar en unión con el conocimiento intelectual. Creando las condiciones para el cuestionamiento sobre asociaciones ya adoptadas como verdaderas y el surgimiento de nuevas posibilidades combinatorias. Los nuevos elementos combinatorios son siempre el resultado de aprehensiones previas que pueden acumularse en la mente del artista desde el nacimiento y allí permanecen como un inmenso banco de datos (Barros, 2003, citado en Fajardo-González, s.f., p. 7).

Los recorridos y conexiones mentales de asociación realizados por el proyectista durante este momento del proceso están condicionados por sus capacidades innatas, pero también por las circunstancias que rodean su práctica, las cuales estimulan la conectividad en su red neuronal. Indudablemente la sustancia imprescindible para fertilizar el proceso es la voluntad motivadora del mundo interior del diseñador.

En un segundo momento, que involucra el pensamiento sistemático, se abren las posibilidades de sistematizar, reflexionar y teorizar sobre la producción propia de arquitectura, y confrontarla con la realidad del mundo exterior al proyectista:

La concreción de la forma arquitectónica (en su sentido amplio) requiere del pensamiento organizado. Es en este nivel que se elaboran explicaciones abstractas llenas de generalidad, objetividad, racionalidad y sistematicidad sobre el objeto en creación. Aquí es donde lo universal trasciende lo concreto, se desenvuelve y desarrolla el conocimiento sobre la disciplina de la Arquitectura, sus paradigmas, teorías y base conceptual. En particular, los proyectistas desarrollan capacidades analógicas en el razonamiento -siempre descansando en una circuitería neuronal genética para organizar conceptos y relacionarlos entre sí. (Salas, 2016, p. 33).

En este momento se reúnen las condiciones imprescindibles para el alcance del nivel académico que aporta al conocimiento de lo proyectual. El acto de proyectar se traslada hacia los territorios de la contrastación, la reflexión, la sistematicidad y la conceptualización. 
El hacer y el saber se funden, y el proyectista observa el presente y el pasado de su producto desde el potencial de ser de lo proyectado, al recorrer el camino de la comunicación de su obra. En el proceso de la conceptualización creativa, el orden metodológico cobra especial importancia, por lo que construir sus protocolos de validación es una tarea perentoria.

Finalmente, la concreción del resultado como producto del acto de creación proyectual se obtiene en un tercer momento, en el que se supera lo general para llegar a lo particular y se establece la identidad definitiva de lo proyectado. La investigación sobre los códigos normativos que limitan la creación proyectual es un tema de reflexión y análisis crítico, trascendente para este momento. Cabe mencionar además que los métodos y técnicas de representación figurativa de la obra proyectada son factores determinantes para la eficacia de la materialización de la arquitectura.

En consonancia con lo mencionado previamente, el desarrollo de los lenguajes de comunicación es estratégico para la difusión de lo producido. En la actualidad, los sistemas de representación de la obra arquitectónica están encaminados mayoritariamente a la materialización y el consumo de la arquitectura, es decir, a su presentación a terceros por medio de lenguajes técnicos (expedientes técnicos de obra) y de mercadeo (visualizaciones fotorrealistas en dos y tres dimensiones). Cabe resaltar en este punto la relación de dependencia que existe entre los objetos creados y los medios para comunicarlos. Ello reafirma la aserción del papel fundamental que juega el lenguaje de imágenes como sistema racionalizador de las experiencias proyectuales y, por ende, del establecimiento de sus límites de entendimiento.

\section{¿Posee una actividad como el proyectar arquitectura los argumentos epistemológicos y metodológicos que requiere un tema para ser reconocido y validado en el ámbito de la investigación académica?}

Tras reconocer el carácter de objeto cognitivo (posible de conocer) de la actividad proyec- tual, que trasciende la mera calificación de oficio (capacidades, habilidades y destrezas en la producción de algo), con la que históricamente se le ha pretendido relegar a un plano cuasi académico, resta discutir los aspectos de naturaleza epistemológica (el conocimiento que encierra) y metodológica (los métodos que le son propios) de la investigación académica correspondiente.

Si la actividad proyectual realizada por el arquitecto cuando diseña implica la reflexión intelectual en torno a sus procesos y productos, ello supone un potencial de búsqueda sistemática de conocimiento. Por supuesto, no se trata de un conocimiento científico, pero no por ello deja de ser conocimiento $y$, mucho menos, de ser útil para contemplar, asimilar y engendrar su realidad de manera sistemática y reflexiva, condiciones básicas para la investigación dentro de la academia. Si, además, una comunidad como la de los proyectistas de arquitectura establece acuerdos sobre la idoneidad de sus particulares métodos de investigación, así como sobre los mecanismos y procedimientos de difusión y validación de sus procesos y resultados, se está ante la consolidación académica de un tipo de investigación específica de la disciplina.

En este sentido, es oportuno mencionar los temas globales relativos a la episteme en arquitectura para identificar los procesos y productos correspondientes a lo proyectual: la zona de intersección entre conocimiento y creación. Para este efecto, conviene hacer un paralelismo entre las artes y la arquitectura, alrededor de la tricotomía investigación sobre el arte, investigación para el arte e investigación en arte:

Research on the arts is research that has art practice in the broadest sense of the word as its object. It refers to investigations aimed at drawing valid conclusions about art practice from a theoretical distance. Ideally speaking, theoretical distance implies a fundamental separation, and a certain distance, between the researcher and the research object[...]Research of this type is common in the meanwhile established academic humanities disciplines, including musicology, art history, theatre studies, media studies and literature. 


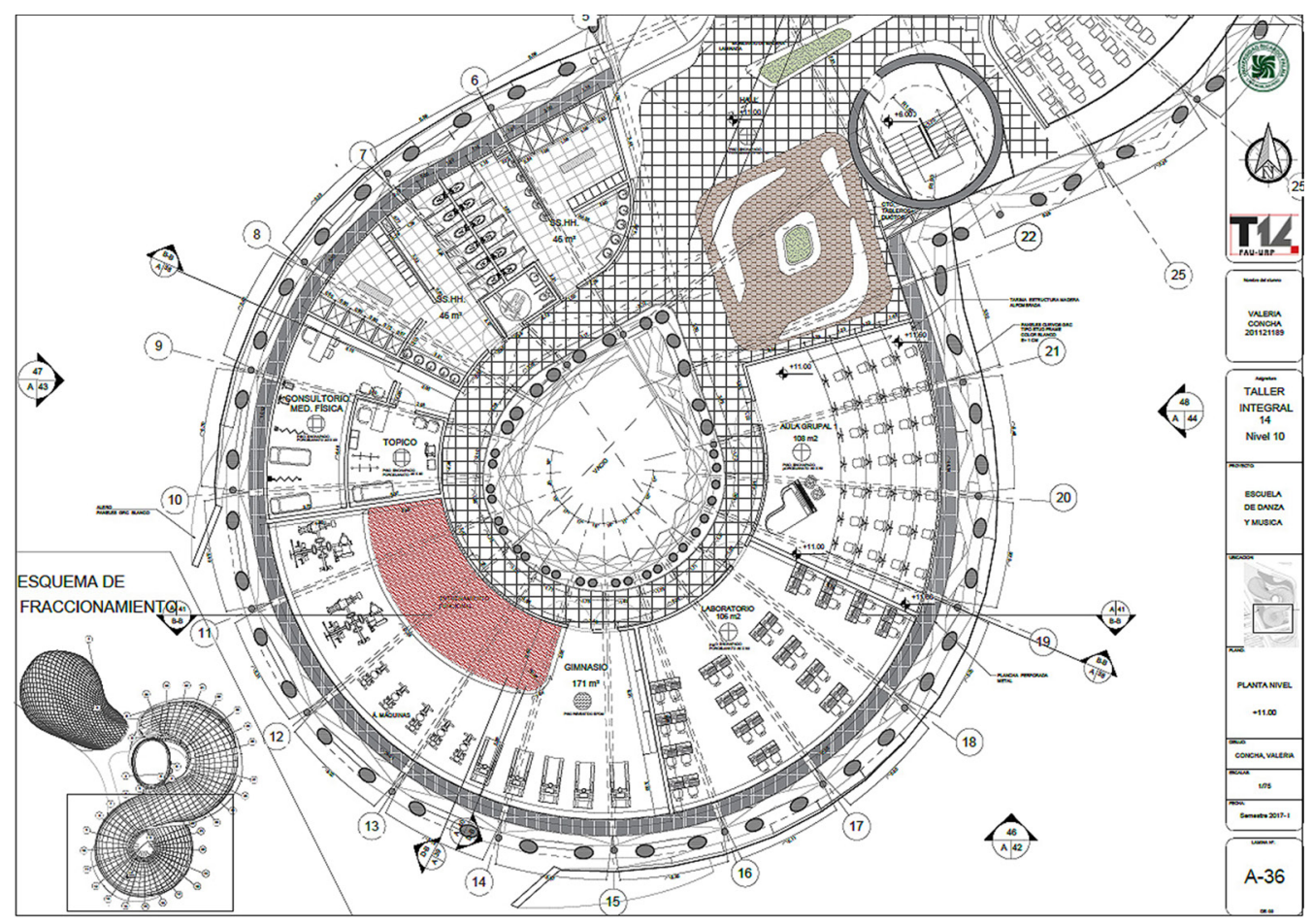

Figura 1. Planta de Escuela de Música y Danza de Barranco. Lima, 2017 [Fotografía por V. Concha, para el trabajo final de Taller integral X, FAU, URP].

Research for the arts can be described as applied research in a narrow sense. In this type, art is not so much the object of investigation, but its objective. The research provides insights and instruments that may find their way into concrete practices in some way or other. Examples are material investigations of particular alloys used in casting metal sculptures, investigation of the application of live electronics in the interaction between dance and lighting design, or the study of the 'extended techniques' of an electronically modifiable cello.

Research in the arts is the most controversial of the three ideal types. Donald Schön speaks in this context of 'reflection in action', and I earlier described this approach as the 'immanent' and 'performative perspective'.

This approach is based on the understanding that no fundamental separation exists between theory and practice in the arts [...]
Concepts and theories, experiences and understandings are interwoven with art practices and, partly for this reason, art is always reflexive. Research in the arts hence seeks to articulate some of this embodied knowledge throughout the creative process and in the art object (Bordoff, 2006, pp. 6-7).

Como se infiere de la cita precedente, la investigación en arquitectura podría clasificarse como investigación sobre arquitectura; para arquitectura y en la arquitectura (a través de lo proyectual). Más allá de las diferencias que indican las preposiciones involucradas, es evidente que son epistemológicamente áreas distintas, aunque todas están contenidas dentro de la misma disciplina.

La investigación sobre arquitectura es aquella que extrae conclusiones a partir del plantea- 
miento y resolución de interrogantes sobre la práctica arquitectónica desde una distancia teórica. Implica una perspectiva interpretativa. La crítica arquitectónica, la historiografía de la arquitectura, entre otras, son áreas del conocimiento que corresponden a este tipo de investigación. La separación entre objeto y sujeto de investigación está en este sustrato, y, por ende, es metodológicamente próxima a las disciplinas sociales y humanísticas relacionadas con la arquitectura. En este sentido, la reflexión e interpretación sobre hechos e ideas pueden tomar características descriptivas o explicativas, críticas y analíticas, o filosóficas, por lo que sus métodos no necesariamente entran en contradicción con aquellos frecuentes en la metodología de las ciencias sociales y humanas.

La investigación para la arquitectura abarca toda aquella que tiene como objetivo nutrirla de componentes de aplicabilidad, es decir, proveer de herramientas y saberes a la práctica arquitectónica. Por lo tanto, se esboza desde una perspectiva instrumental. La investigación de tecnologías, materiales y sistemas constructivos, o de avances en materia de realidad aumentada, por ejemplo, son resultado de una investigación al servicio de la producción proyectual. Los métodos asociados a este tipo de investigación aplicada dependen, en gran medida, de cada campo específico de interés.

La investigación en arquitectura es en realidad la investigación que se realiza a través del proyectar arquitectura, por medio de la propia producción proyectual. Allí sujeto y objeto articulan sus identidades, subyacentes en la práctica. Se trata de un viaje reflexivo hacia el interior del proyectista, a partir de su acción. Tal como en el arte, la producción arquitectónica es el proyecto en sí, el cual puede alcanzar el nivel de investigación académica. Su singularidad corresponde a que cuenta con su propio thelos y lenguaje. Es posible, por lo tanto, que el proyectista trabaje en el proceso de su obra arquitectónica y, simultánea y sistemáticamente, construya reflexivamente un discurso propio sobre tal proceso:
El arte no es discurso, es acto. La obra artística se elabora a través de gestos, procedimientos, procesos que no pasan por lo verbal y no dependen de él. Su instrumento es plástico, soportes, materiales, colores, líneas, formas, volumen. Lo que resulta es un objeto presente en su condición física, independiente de todo y cualquier discurso, inclusive aquel del propio artista (Cattani, 2002, citado en FajardoGonzález, s.f., p. 3).

Tal como los otros tipos de investigación académica, la investigación proyectual permite plantear interrogantes articuladas y resolver problemas claramente formulados, y establecer el estado del arte específico y la contribución del proyecto al área de conocimiento aplicando métodos validados en su lenguaje natural de comunicación. Sus resultados pueden ser claramente documentados, difundidos y sometidos al juicio crítico de pares. En este sentido, es similar a cualquier otra clase de investigación académica: su finalidad es, esencialmente, el aumento del conocimiento en su área de saber, de acuerdo con criterios de originalidad y rigurosidad. Si esta afirmación es aceptable, ¿por qué entonces se presenta resistencia ante el intento de definirla como tal? Es probable que la explicación se deba a la incomprensión de los métodos y lenguajes que emplea.

\section{Aspectos metodológicos}

Si la metodología, entendida como la sistematización de los procesos de investigación con miras a obtener un objetivo específico, requiere avalarse por estándares y convenciones consensuadas, la pregunta pertinente es cuáles serían los métodos propios de la investigación en lo proyectual, y si estos necesariamente deben ser distintos de aquellos empleados en la investigación científica, y, en ese caso, en qué términos lo serían. Ahora bien, si la investigación en lo proyectual es esencialmente subjetiva, los métodos también tendrían que serlo. Esto sugiere un problema de convalidación, pues habría tantos métodos como investigadores proyectistas.

¿Cuáles son los tipos de método que corresponden a la investigación desde lo proyectual? ¿Surgen de la fuente de lo empírico-de- 
ductivo, propia de la experimentación en las ciencias naturales; deben ser más bien aquellos relacionados con el análisis cuantitativo de información; o tal vez la observación participante del comportamiento de un fenómeno -empleada en los estudios etnográficos-, orientada más a su interpretación, y no a su descripción o explicación detalladas? Al establecer una semejanza con la investigación en las artes, Bordoff (2006) plantea que "Hence, the answer to the question of art research methodology is briefly that the research design incorporates both experimentation and participation in practice and the interpretation of that practice" (pp. 17-18). La metodología en lo proyectual, por tanto, integra la particular visión del proyectista sobre el proceso y producto de su obra (construcción de imágenes reflexivas de su propia obra) utilizando métodos hermenéuticos y experimentales.

\section{Métodos y lenguaje}

Los métodos están indudablemente condicionados por los lenguajes que les son propios. En este punto se debe diferenciar el lenguaje particular del objeto arquitectónico ya edificado: el de las formas y espacios, percibidos a través del sentido visual. Se trata del lenguaje de la realidad arquitectónica, una vez materializada:

Sostenemos que el lenguaje de la Arquitectura son las formas espaciales, que vienen a ser el léxico de que se vale para expresarse artísticamente. Son ellas el modo de expresión específico de la Arquitectura, y, si bien encontramos espacio en otras clases de Arte, como Pintura y Escultura, sólo en la Arquitectura es el "verbo" del lenguaje artístico, aquel que subordina a sí mismo el significado de todos los otros elementos.

Este lenguaje de las formas espaciales se concreta en un espacio artístico, es decir, es un espacio transformado (transfigurado, sublimado) que es un lugar (espacio limitado) donde se vive y se actúa pero que, gracias al lenguaje arquitectónico, ya no es solamente un espacio concreto práctico, sino una creación humana, de carácter abstracto, espiritual, ya que no es solamente el lugar de nuestra estadía o de nuestra curiosidad turística, sino la "poe- sía" del arquitecto; ha volcado en esos espacios toda su propia expresión, que no sólo van a satisfacer específicas necesidades primarias, sino que espiritualizándolas, revelan la plena humanización que permite al hombre "vivir" integralmente esos espacios creados para él. (Ivelic, 1969, p. 44)

Muy distante del lenguaje de la arquitectura como hecho materializado, se encuentra el lenguaje de la investigación proyectual, aquel que trata de reproducir el objeto y el proceso que lo engendró (para su comprensión), con la finalidad de aumentar el conocimiento en esta área del saber. Se trata del devenir de la huella de una realidad arquitectónica, previa a su materialización como obra. Este es, en definitiva, un lenguaje de imágenes.

Para comprender mejor la calidad de esencial del lenguaje de las imágenes en el proyectar de arquitectura, es necesario hacer referencia a Villafañe (2006) y su propuesta de aclarar el concepto de imagen situándola en el plano de lo icónico:

Los cuatro tipos a los que me refiero son las imágenes mentales, las naturales, las creadas y las registradas. Las dos primeras son imágenes no manipuladas, al contrario que las dos restantes. Obtenidas mediante un sistema de registro que puede ser manual o mecánico, Las imágenes mentales poseen, por paradójico que esto parezca, gran parte de las características de la naturaleza icónica «convencional». Tienen un contenido sensorial; suponen modelos de realidad, en muchos casos altamente abstractos; tienen, por tanto, un referente. etc.

Las imágenes naturales son aquellas que el individuo extrae del entorno que le rodea cuando existen unas condiciones lumínicas que permitan la visualización. Son las imágenes de la percepción ordinaria.

En las imágenes creadas, además de las anteriores, hay que contar con la mediación del material, que generalmente afecta sobremanera al resultado visual de la imagen. Una última característica de las imágenes creadas, común también a las mentales, es que no necesitan inexcusablemente la presencia del referente para producirse. Las imágenes sin duda más complejas, desde un punto de vista material al menos, son las registradas. 
La mayor parte de estas imágenes tienen una clara intención comunicativa[...]Está claro que una obra pictórica es un ejemplo de imagen creada y que la fotografía de nuestro carné de identidad lo es de imagen registrada (p. 45).

La modelación icónico-abstracta de esta realidad -a través de las imágenes de lo proyectado- es el componente principal de la expresión, percepción y representación del producto arquitectónico investigado y su proceso generador. Se trata de una determinada modelación de la realidad creada por el proyectista-investigador sobre la base de los aspectos visuales de la percepción humana. Esta modelación, que varía entre lo icónico y lo abstracto, proviene de la capacidad humana de imaginar, es decir, de producir imágenes.

Para discutir sobre el grado de iconicidad de imágenes que representaría lo proyectado, es apropiado referirse a los tres diferentes momentos involucrados en la creación arquitectónica postulados anteriormente: el dominado por la intuición, el del pensamiento racional y el de la concreción técnica. En ellos la modelación de la realidad realiza movimientos sinuosos entre la iconicidad y la abstracción. Para llevar a cabo un primer intento por descubrir qué imágenes podrían estar asociadas a un lenguaje de comunicación de lo proyectado, se considera conveniente presentar la clasificación realizada por Villafañe (2006) sobre la imagen y su iconicidad (ver Tabla 1).

Como lo establece el autor, cada uno de estos niveles puede agruparse en categorías de acuerdo con su función pragmática. De este modo, la imagen natural tendrá una función de reconocimiento, mientras que el modelo tridimensional a escala, las imágenes de registro estereoscópico, y la fotografía a color y blanco y negro son esencialmente descriptivas. Por otro lado, la pintura realista y la representación figurativa no realista pertenecen al mundo de la representación artística. Los pictogramas, los esquemas motivados y los arbitrarios se emplean en el ámbito de la expresión de las ideas y, en ocasiones, en la comunicación con terceros involucrados en la actividad proyectual. Finalmente, la repre- sentación figurativa es propia de la búsqueda creativa (Villafañe, 2006).

En el primer momento de la creación arquitectónica, los grados de iconicidad más empleados son los del rango entre uno (1) y cuatro (4), pues implican un mayor nivel de abstracción; la abstracción parece ser el primer paso auténtico de la mente creativa para expresar lo intuido. Posteriormente, en el momento de la conceptualización creativa, es probable que la iconicidad de lo proyectado se extienda hasta el grado seis (6), que involucra territorios ambiguos entre la abstracción y el realismo. Finamente, los grados de las imágenes correspondientes a los niveles siete (7), ocho (8), nueve (9) y diez (10) sugieren funciones de representación descriptiva de los atributos del objeto arquitectónico, tradicionalmente relacionadas con el lenguaje del dibujo técnico y la modelación tridimensional a escala de lo edificable.

\section{Reflexiones finales}

Como quedó establecido en las palabras iniciales de este trabajo, la pertinencia de reconocer a la actividad de proyectar arquitectura como sujeto de investigación académica reside en la necesidad de elevarla a un plano superior del conocimiento, ampliando las fronteras de la comprensión y difusión de sus saberes. Se trata de una forma nueva de descubrir el conocimiento a través de los atávicos quehaceres de los procesos de creación arquitectónica. El reto de otorgarle nivel académico a la investigación proyectual es una de las urgentes tareas de quienes se dedican a ello.

En la base de la definición de investigación aparece la genuina curiosidad intelectual. Esta se expresa por medio de la formulación de preguntas pertinentes en el contexto del investigador y en el mundo de la arquitectura en general. Por supuesto, la congruencia de tales interrogantes debe ser avalada por un examen del estado de la cuestión investigada, una revisión sistemática y exhaustiva de lo conocido sobre el tema. He ahí una evidente coincidencia entre las investigaciones sobre, para y a través de la actividad proyec- 
tual de la arquitectura. Se debe estimular que los proyectistas investigadores realicen una amplia cobertura del estado del arte sobre el tema investigado, que trascienda las evidencias de los resultados y descubra los procesos que las han generado.

El rigor es otro aspecto en el que concurren los diferentes tipos de investigación en ar- quitectura. Toda investigación académica requiere expresar sus formas y contenidos con la rigurosidad indispensable. Pero, ¿cómo se podría establecer estándares de rigor en un ambiente en el que se cultiva la creatividad individual en el proceso de proyectar? Cada diseñador desarrolla sus muy particulares estándares de rigurosidad, lo que en apariencia

Tabla 1. Escala de iconicidad para la imagen fija-aislada

\begin{tabular}{|c|c|c|c|}
\hline Grado & Nivel de realidad & Criterio & Ejemplo \\
\hline 11 & $\begin{array}{l}\text { La imagen } \\
\text { natural }\end{array}$ & $\begin{array}{l}\text { Restablece todas las propiedades del obje- } \\
\text { to, etc. Existe identidad. }\end{array}$ & $\begin{array}{l}\text { Cualquier percepción de la rea- } \\
\text { lidad sin más mediación que las } \\
\text { variables físicas del estímulo }\end{array}$ \\
\hline 10 & $\begin{array}{l}\text { Modelo tridi- } \\
\text { mensional a } \\
\text { escala }\end{array}$ & $\begin{array}{l}\text { Restablece todas las propiedades del } \\
\text { objeto, etc. Existe identificación, pero no } \\
\text { identidad. }\end{array}$ & La Venus de Milo \\
\hline 9 & $\begin{array}{l}\text { Imágenes de } \\
\text { registro este- } \\
\text { reoscópico }\end{array}$ & $\begin{array}{l}\text { Restablece la forma y posición de los } \\
\text { objetos emisores de radiación presentes en } \\
\text { el espacio. }\end{array}$ & Un holograma \\
\hline 8 & $\begin{array}{l}\text { Fotografía a } \\
\text { color }\end{array}$ & $\begin{array}{l}\text { Cuando el grado de definición de la imagen } \\
\text { está equiparado al poder resolutivo del ojo } \\
\text { medio }\end{array}$ & $\begin{array}{l}\text { Fotografía en la que un círculo } \\
\text { de un metro de diámetro situa- } \\
\text { do a mil metros sea visto como } \\
\text { un punto }\end{array}$ \\
\hline 7 & $\begin{array}{l}\text { Fotografía en } \\
\text { blanco y negro }\end{array}$ & Igual que el anterior. & Igual que el anterior \\
\hline 6 & Pintura realista & $\begin{array}{l}\text { Restablece razonablemente las relaciones } \\
\text { espaciales en un plano bidimensional. }\end{array}$ & Las Meninas de Velázquez \\
\hline \multirow[t]{2}{*}{5} & \multirow{2}{*}{$\begin{array}{l}\text { Representación } \\
\text { figurativa no } \\
\text { realista }\end{array}$} & \multirow{2}{*}{$\begin{array}{l}\text { Aún se produce la identificación, pero las } \\
\text { relaciones espaciales están alteradas. }\end{array}$} & Guernica de Picasso \\
\hline & & & Una caricatura de Peridis \\
\hline 4 & Pictograma & $\begin{array}{l}\text { Todas las características sensibles. Excepto } \\
\text { la forma. Están abstraídas. }\end{array}$ & Siluetas, monigotes infantiles \\
\hline 3 & $\begin{array}{l}\text { Esquemas } \\
\text { motivados }\end{array}$ & $\begin{array}{l}\text { Todas las características sensibles abstraí- } \\
\text { das. Tan sólo restablecen las relaciones } \\
\text { orgánicas. }\end{array}$ & Organigramas, planos \\
\hline 2 & $\begin{array}{l}\text { Esquemas } \\
\text { arbitrarios }\end{array}$ & $\begin{array}{l}\text { Todas las características sensibles abstraí- } \\
\text { das. Las relaciones de dependencia entre } \\
\text { sus elementos no siguen ningún criterio } \\
\text { lógico. }\end{array}$ & $\begin{array}{l}\text { La señal de circulación que } \\
\text { indica "ceda el paso" }\end{array}$ \\
\hline 1 & $\begin{array}{l}\text { Representación } \\
\text { no figurativa }\end{array}$ & $\begin{array}{l}\text { Tienen abstraídas todas las propiedades } \\
\text { sensibles y de relación. }\end{array}$ & Una obra de Miró \\
\hline
\end{tabular}

Adaptado de Introducción a la Teoría de la Imagen (pp. 41-42), por J. Villafañe, 2006, Madrid, España: Pirámide. 
dificultaría la comparación y valoración de métodos y resultados. No obstante, el jurado más severo de una obra de arquitectura es el propio autor, debido a la condición de inconformidad inherente a la actuación creativa; por supuesto, la exposición ante los pares es el tribunal más apropiado.

La difusión de resultados y procesos de la investigación proyectual es una condición vital, siempre que se dé dentro de unos estándares de publicación exclusivos y validados por la comunidad académica. Presentar y exponer la propia investigación a la crítica de pares es otro requerimiento sine qua non. Sin ello será imposible su validación. Es un mandato para la comunidad de arquitectos de la academia promover la aparición y continuidad de todo tipo de formas de publicación de resultados de investigación. Ello puede tomar formas clásicas (impresas), pero también puede realizarse mediante exposiciones y exhibiciones

\section{Referencias}

Bordoff, H. (2006). The debate on research in the Arts. Recuperado de http://www.pol.gu.se/ digitalAssets/1322/1322713_the_debate_on_research_in_the_arts.pdf

Chacón, J. L. (2013, julio-diciembre). Bases teóricas del proyecto como investigación en la enseñanza universitaria. Propuesta y ejemplo de implementación en la Escuela de Arquitectura de la ULA. M. Revista de la Facultad de Arquitectura de la Universidad Santo Tomás, 10, 11.

Fajardo-González, R. (s.f.). La investigación en el campo de las Artes Visuales y el ámbito académico universitario (Hacia una perspectiva semiótica) 3. Recuperado de https://www.google.com.pe/url ? $\mathrm{sa}=\mathrm{t} \& \mathrm{rct}=\mathrm{j} \& \mathrm{q}=\&$ esrc $=\mathrm{s} \&$ source $=$ web $\& \mathrm{~cd}=1 \& \mathrm{cad}$ $=$ rja\&uact $=8 \&$ ved $=$ oahUKEwjCmqqKx__UAhUB FT4KHRYxBoQQF ggkMAA\&url=http $\% 3 \mathrm{~A} \% 2 \mathrm{~F} \% 2$ Fwww.unav.es\%2Fgep\%2FInvestigacionArtesFajardo. pdf\&usg=AFQjCNEJSjdheglunETLLOmwnb9H OG_b5Q temporales. La finalidad fundamental de todas ellas no es tener un impacto únicamente en el mundo académico, sino además en el profesional.

Quizá el desafío más importante de la investigación proyectual se halle en consolidar un lenguaje natural consensuado para los diversos momentos del proceso de creación arquitectónica y la consiguiente investigación derivada de este. Se habrá hecho evidente en el discurso del presente ensayo que este lenguaje habita un universo híbrido de imágenes, en sus diversos niveles de abstracción e iconicidad. Se nutre de un estilo conciso y a la vez digresivo para expresar, representar y exponer los procesos de la creación arquitectónica. Aquí los proyectistas investigadores deben tender los puentes necesarios para establecer los componentes básicos de tal lenguaje, para así convertirlo en una herramienta eficaz de comunicación.
Hernández, F. H. (2008). La investigación basada en las artes. Propuestas para repensar la investigación en la educación. Educatio Siglo XXI, (26), 87-88.

Ivelic, M. (1969). El lenguaje arquitectónico. Aisthesis, (4), 44.

Martínez, A., \& Ríos, F. (2005). Los conceptos de conocimiento, epistemología y paradigma, como base diferencial en la orientación metodológica del trabajo de grado. Cinta de Moebio. Recuperado de http:// www.redalyc.org/articulo.oa?id $=10102508$

Salas, J. D. (2016, agosto-diciembre). El aprendizaje del arte de proyectar arquitectura. Entre ideologías y prácticas. $P \& A,(1), 32$.

Villafañe, J. (2006). Introducción a la teoría de la imagen. Madrid, España: Pirámide. 